\title{
Tolerability of budesonide/formoterol in patients of Kazakhstan rural regions
}

\author{
Tair Nurpeissov*, Temyrzhan Nurpeissov², Gulzada Abdushukurova² ${ }^{2}$ Aizhan Avdugalieva² ${ }^{2}$, Meruert Gazaliyeva², \\ Alima Shagiyeva ${ }^{2}$
}

From 2nd International Severe Asthma Forum (ISAF)

Athens, Greece. 13-15 November 2014

\section{Background}

Despite all our measures, rates of the allergic diseases in Kazakhstan is steadily increasing every year. Drug allergy and in particular allergic reactions to asthma medication is also a growing problem.

The aim of this study was to assess the frequency of budesonide/formoterol adverse effects.

\section{Methods}

Ninety-three patients with moderate to severe uncontrolled asthma from rural outpatient clinics were included in this study. 54 women and 39 men, their age ranged from 19 to 61 years (average 35.6 \pm 4.53 ). None of them has ever used the combination of budesonide and formoterol before. Every subject underwent a 3-month treatment with budesonide/formoterol, daily doses of budesonide ranged from 640 to $960 \mathrm{mcg}$ depending on the severity of the disease. Tolerability of budesonide/formoterol and its adverse effects occurrence were evaluated.

\section{Results}

Only $5.4 \%$ of subject group experienced one or another adverse effect and only in one case, it was sufficient reason to stop the treatment. Patient experienced rapid angioedema with upper airway obstruction on the very first day of treatment. It is necessary to notice, that he has severe polyvalent drug allergy and cannot tolerate majority of other anti-asthmatic drugs. Only other adverse effect that occurred during treatment (in $4.3 \%$ of cases) is xerostomia (mouth dryness). It was easily eliminated by rinsing the mouth.

'SRI of Cardiology and Internal Diseases, ALMATY, Kazakhstan

Full list of author information is available at the end of the article

\section{Conclusions}

The combination of budesonide and formoterol showed good tolerability with only 5 cases of adverse effects, majority of which $(80 \%)$ were easily eliminated and didn't become a reason to stop treatment.

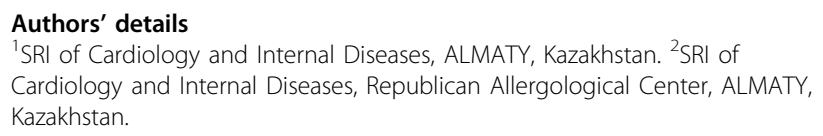

Published: 23 March 2015

\section{doi:10.1186/2045-7022-5-S2-P21}

Cite this article as: Nurpeissov et al:: Tolerability of budesonide/ formoterol in patients of Kazakhstan rural regions. Clinical and Translational Allergy 2015 5(Suppl 2):P21.

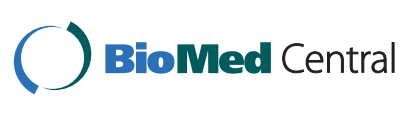

(c) 2015 Nurpeissov et al; licensee BioMed Central Ltd. This is an Open Access article distributed under the terms of the Creative Commons Attribution License (http://creativecommons.org/licenses/by/4.0), which permits unrestricted use, distribution, and reproduction in any medium, provided the original work is properly cited. The Creative Commons Public Domain Dedication waiver (http://creativecommons.org/publicdomain/zero/1.0/) applies to the data made available in this article, unless otherwise stated.

Submit your next manuscript to BioMed Central and take full advantage of:

- Convenient online submission

- Thorough peer review

- No space constraints or color figure charges

- Immediate publication on acceptance

- Inclusion in PubMed, CAS, Scopus and Google Scholar

- Research which is freely available for redistribution 